\title{
Optimal Design of a Surface Mounted Permanent-Magnet BLDC Motor for Spacecraft Applications
}

\author{
R.P. Praveen ${ }^{1}$, M.H. Ravichandran ${ }^{2}$, V.T. Sadasivan Achari ${ }^{3}$, Dr. V.P. Jagathy Raj ${ }^{4}$, Dr. G. Madhu ${ }^{5}$, \\ Dr. G.R. Bindu ${ }^{6}$, and Dr. F. Dubas ${ }^{7}$
}

\begin{abstract}
This paper presents the optimal design of a surface mounted permanent-magnet (PM) Brushless directcurrent (BLDC) motor meant for spacecraft applications. The spacecraft applications requires the choice of a motor with high torque density, minimum cogging torque, better positional stability and high torque to inertia ratio. Performance of two types of machine configurations designed viz Slotted PMBLDC and Slotless PMBLDC with Halbach array and radial magnetization are compared with the help of analytical and finite-element (FE) methods. It is found that unlike a Slotted PMBLDC motor, the Slotless type with Halbach array develops zero cogging torque without reduction in the developed torque, suiting spacecraft applications. Moreover, the machine being coreless provides high torque to inertia ratio and zero magnetic stiction confirming to the requirements of spacecraft applications.
\end{abstract}

Keywords: Brushless DC motor, slotted, slotless, Halbach, torque, cogging, space application.

\section{Nomenclature}

$R_{s y} \quad$ Radius of the stator yoke surface

$R_{s} \quad$ Radius of the stator surface

$R_{m} \quad$ Radius of the Permanent Magnets surface

$R_{r} \quad$ Radius of the rotor yoke surface

$\theta_{m} \quad$ Mechanical angle of the Permanent Magnets

$\theta_{0} \quad$ Mechanical angle of stator slot opening

$\theta_{t} \quad$ Mechanical angle of stator tooth pitch

$\theta_{p} \quad$ Mechanical angle of a pole-pitch

$B_{r m} \quad$ Remanent flux density of Permanent Magnets

$\mu_{r m} \quad$ Relative recoil permeability of Permanent Magnets

$p \quad$ Number of pole pairs

$n \quad$ Spatial harmonic order

$v \quad$ Slotting harmonic order

$M_{r} \quad$ Radial Component of Magnetization

$M_{\theta} \quad$ Tangential Component of Magnetization

$A_{z} \quad$ No-load magnetic vector potential

$f_{z}, f_{\theta}$ Dimensionless function in fourier series

\section{Introduction}

The BLDC motors have been proven to be the best all-around type of motors for aerospace applications because of their long life, high torque, high efficiency, and low heat dissipation [1]. The torque produced in a Slotted PMBLDC motor can be classified as alignment torque (i.e., useful torque) and cogging torque. The alignment torque is produced due to the interaction of the PM with the stator conductors and the cogging torque is caused by the variation of the magnetic energy stored in the air-gap, due to the PM flux with the angular position of the rotor. Thus cogging torque is produced due to the interaction between the rotor magnetic flux and the variation of stator reluctance caused by slotting [2-6]. For high performance applications, such as in robotics and space applications requiring utmost accuracy, torque smoothness is essential [7]. Hence, it is very important to consider torque ripple minimization and its related harmonics without affecting the developed torque of the machine. The presence of cogging torque, which is one of the main factors contributing to the torque ripple is an inherent disadvantage faced in the slotted motor design.

The Attitude Control Systems (ACS) for future spacecraft applications requires an ideal choice of motor that has high torque density, zero cogging torque, high positional stability, high torque to inertia ratio and zero magnetic stiction. Stepper motors, a special case of BLDC motors cannot be used for critical ACS applications because of its high ripple torque, which affects the precise positioning requirement of the application. Moreover, the research works carried out by the authors [8-9] clearly reveal the magnitude of the detent torque present in the stepper motor which is almost $13 \%$ of the developed torque. This magnitude is very high than the actual requirement which warrants minimum cogging torque, ideally zero for critical space applications. A slotless BLDC motor design however eliminates the tooth ripple component of cogging as well as has little slot harmonic effects thereby facilitating the need of smooth torque output required for the application.

A slotless machine, however suffers from a generally lower magnetic flux crossing the motor air-gap which results in a lower power output in the slotless design compared to an equivalent slotted design [10-11]. This reduction in the magnetic flux crossing the air-gap is compensated by the use of Halbach magnetized array, having strong and uniform magnetic field.

As per the requirements of the spacecraft application, the outer diameter and axial length of the machine is 
selected as $104 \mathrm{~mm}$ and $40 \mathrm{~mm}$ respectively. Hence a design has been developed in accordance with the specifications for spacecraft applications. For clarity, the paper is further divided in to three sub-sections in which section II deals with the analytical modeling and FE optimization of a slotted PMBLDC motor. Section III and IV elaborates the analytical modeling, FE optimization and comparison with a slotless PMBLDC motor configuration.

\section{Analysis of a Slotted PMBLDC Motor}

\section{II.1. Analytical Modeling}

An exact analytical solution (i.e., the Maxwell's equation applied in sub-domain) is developed for calculating the no load magnetic flux density of a slotted PMBLDC motor with the effect of slotting considered. Fig. 1 shows the cross section of a slotted PMBLDC motor under one pole pitch.

The main parameters of this geometry are: the radius of the stator yoke surface- $R_{s y}$, the radius of the stator

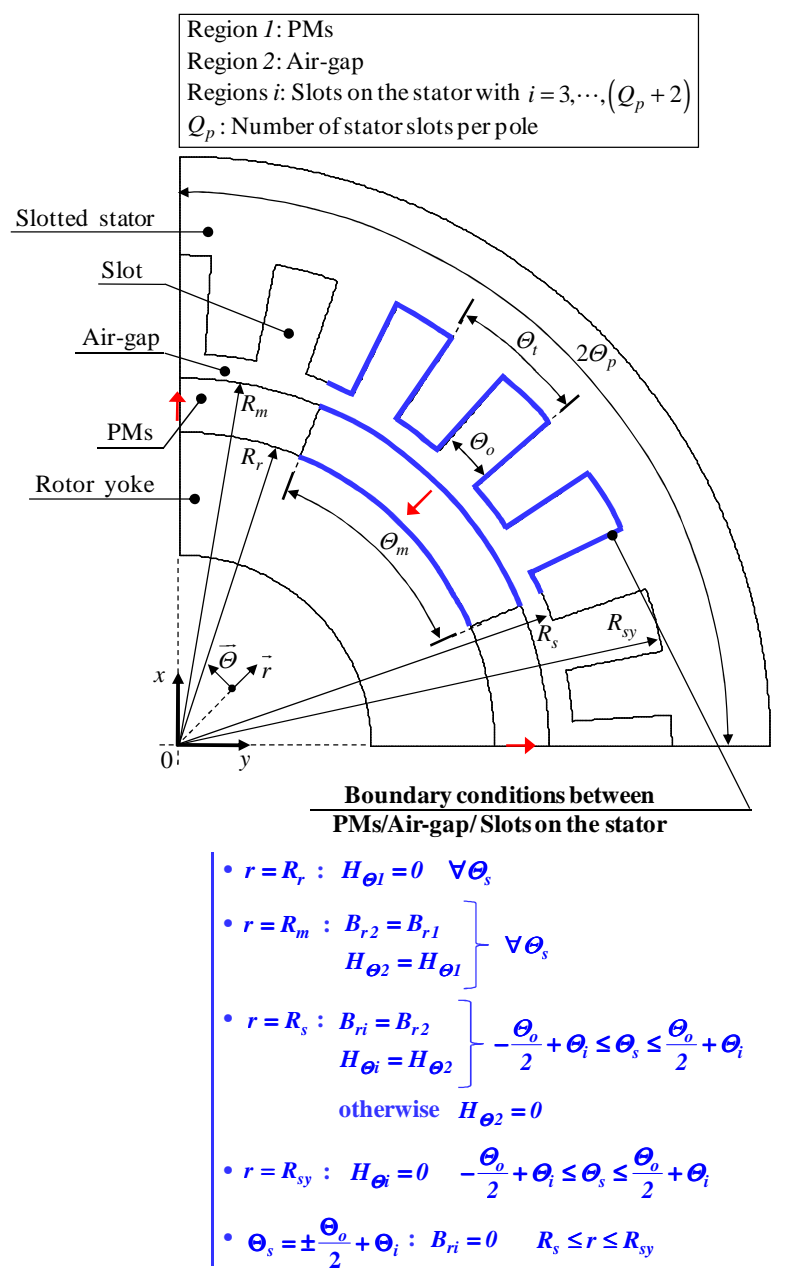

Fig. 1. Cross section under one pole pitch of a slotted PMBLDC Motor [12] surface- $R_{s}$, the radius of the PMs surface- $R_{m}$, the radius of the rotor yoke surface- $R_{r}$, the mechanical angle of PMs- $\Theta_{m}$, the mechanical angle of a stator slotopening- $\Theta_{o}$, the mechanical angle of a stator tooth-pitch$\Theta_{t}$, and the mechanical angle of a pole-pitch- $\Theta_{p}$.

The following assumptions are made for developing the analytical model of a surface mounted slotted type PMBLDC motor similar to that followed in many models of the literature [12-14]:

i) End-effects are neglected

ii) The stator and rotor back-iron is infinitely permeable (i.e., the magnetic saturation is neglected)

iii) The electrical conductivity of the PMs is assumed to be null to calculate the no-load magnetic vector potential (i.e., non-resolution of Diffusion's equations)

iv) The PMs are assumed to be nonoriented, isotropic, and having a linear demagnetization characteristic (rare earth magnets)

v) The stator slot faces are radial as shown in Fig. 1 .

The exact analytical model is based on 2-D analysis in polar coordinates. It involves the solution of Laplace's equations in the air-gap (i.e., concentric region: Region 2) and in the slots on the stator (i.e., non-concentric regions: Regions $i$ ) and the solution of Poisson's equations in the PMs (i.e., concentric region: Region 1) [Fig. 1] with constant magnetic permeabilities. The no-load magnetic vector potential in the air-gap, PMs and slots are given by,

$$
\begin{aligned}
& \Delta A_{z 1}=-\frac{\mu_{0}}{r} \cdot\left(M_{\Theta}-\frac{\partial M_{r}}{\partial \Theta_{s}}\right) \text { in Region } 1, \\
& \Delta A_{z 2}=0 \text { in Region } 2, \\
& \left.\Delta A_{z i}=0 \text { in Regions } i \text { (for } I=0 \mathrm{~A}\right),
\end{aligned}
$$

where $A_{z 1} \sim A_{z i}$ are the no-load magnetic vector potential in different regions, $\mu_{0}$ is the vacuum permeability, $M_{r}$ and $M_{\Theta}$ are respectively the radial and tangential components of the magnetization $\vec{M}, r$ and $\Theta_{s}$ are respectively the radial position and the mechanical angular position of the stator (the position $\Theta_{s}=0$ is the center of a slot).

By combining (1) with the boundary conditions at the interface between the various regions [Fig. 1] and by using the method of separating variables, the no-load magnetic vector potential solutions with the slotting effect can be determined in Fourier's series. The magnetic vector potential as well as the radial and tangential components for the magnetic flux density developed by one of the authors [12] at no-load are expressed in various regions by the following equations:

In the PMs (i.e., Region 1) by

$$
\begin{aligned}
& A_{z 1}=B_{r m} \cdot R_{m} \cdot f_{z 1}\left(r, \Theta_{s}\right) \forall n p, \\
& B_{r 1}=B_{r m} \cdot f_{r l}\left(r, \Theta_{s}\right) \forall n p
\end{aligned}
$$


$B_{\Theta I}=B_{r m} \cdot f_{\Theta I}\left(r, \Theta_{S}\right) \quad \forall n p$,

(2c)

In the air-gap (i.e., in Region 2) by

$$
\begin{aligned}
& A_{z 2}=B_{r m} \cdot R_{m} \cdot f_{z 2}\left(r, \Theta_{s}\right) \forall n p, \\
& B_{r 2}=B_{r m} \cdot f_{r 2}\left(r, \Theta_{s}\right) \forall n p, \\
& B_{\Theta 2}=B_{r m} \cdot f_{\Theta 2}\left(r, \Theta_{s}\right) \forall n p,
\end{aligned}
$$

In the slots on the stator (i.e., Regions $i$ ) by

$$
\begin{aligned}
& A_{z i}=B_{r m} \cdot R_{s} \cdot f_{z i}\left(r, \Theta_{s}\right) \forall v, \\
& B_{r i}=B_{r m} \cdot f_{r i}\left(r, \Theta_{s}\right) \forall v, \\
& B_{\Theta i}=B_{r m} \cdot f_{\Theta i}\left(r, \Theta_{S}\right) \forall v,
\end{aligned}
$$

where $B_{r m}$ is the remanent flux density of PMs; $p$ is the number of pole pairs; $n$ and $v$ are the spatial and the slotting harmonic orders respectively; $f_{z 1} \sim f_{\Theta i}$ are the dimensionless functions in Fourier's series which depend respectively on the integration constants $E_{1 n} \& G_{1 n}$ in Region 1, $E_{2 n} \sim H_{2 n}$ in Region 2, and $F_{i v}$ in Regions $i$, [12].

The above coefficients $E_{1 n}, G_{1 n}, E_{2 n} \sim H_{2 n}$ and $F_{i v}$ are determined by numerically solving the linear equations given above (i.e., the Cramer's system) for each $\Theta_{r s}$ (with $\Theta_{r s}$ the mechanical angular position between the rotor and the stator). The matrix representing the integration constants, $[I C]$ is given by:

$$
[I C]=[Q]^{-1} \cdot[K]
$$

$\begin{aligned} {[I C] } & =\left[\begin{array}{c}E_{1 n} \\ E_{2 n} \\ F_{2 n} \\ G_{1 n} \\ G_{2 n} \\ H_{2 n} \\ F_{3 v} \\ F_{4 v} \\ \vdots \\ F_{\left(Q_{p}+2\right) v}\end{array}\right] \text { and }[K]=\left[\begin{array}{c}K_{1 n} \\ K_{3 n} \\ 0 \\ K_{2 n} \\ K_{4 n} \\ 0 \\ 0 \\ 0 \\ \vdots \\ 0\end{array}\right], \\ {[Q] } & =\left[\begin{array}{ccc}Q_{A} & 0 & Q_{B} \\ 0 & Q_{A} & Q_{C} \\ Q_{D} & Q_{E} & Q_{F}\end{array}\right],\end{aligned}$

where

$$
Q_{A}=\left[\begin{array}{ccc}
Q_{1 n n} & Q_{0 n n} & Q_{0 n n} \\
Q_{2 n n} & -Q_{0 n n} & Q_{0 n n} \\
0 & Q_{3 n n} & Q_{4 n n}
\end{array}\right],
$$

$$
\begin{aligned}
Q_{B} & =\left[\begin{array}{cccc}
0 & 0 & \cdots & 0 \\
0 & 0 & \cdots & 0 \\
Q_{5 n v 3} & Q_{5 n v 4} & \cdots & Q_{5 n v}\left(Q_{p}+2\right)
\end{array}\right], \\
Q_{C} & =\left[\begin{array}{cccc}
0 & 0 & \cdots & 0 \\
0 & 0 & \cdots & 0 \\
Q_{6 n v 3} & Q_{6 n v 4} & \cdots & Q_{6 n v\left(Q_{p}+2\right)}
\end{array}\right], \\
Q_{D} & =\left[\begin{array}{cccc}
0 & Q_{7 v n 3} & & Q_{8 v n 3} \\
0 & Q_{7 v n 4} & & Q_{8 v n 4} \\
\vdots & \vdots & & \vdots \\
0 \square & Q_{7 v n\left(Q_{p}+2\right)} & Q_{8 v n}\left(Q_{p}+2\right)
\end{array}\right], \\
Q_{E} & =\left[\begin{array}{cccc}
0 & Q_{9 v n 3} & & Q_{10 v n 3} \\
0 & Q_{9 v n 4} & & Q_{10 v n 4} \\
\vdots & \vdots & & \vdots \\
0 \square & Q_{9 v n}\left(Q_{p}+2\right) & Q_{10 v n}\left(Q_{p}+2\right)
\end{array}\right], \\
Q_{F} & =\left[\begin{array}{cccc}
Q_{11 v v 3} & 0 & \cdots & 0 \\
0 & Q_{11 v v 4} & \cdots & 0 \\
\vdots & \vdots & \ddots & \vdots \\
0 & 0 & \cdots & Q_{11 v v\left(Q_{p}+2\right)}
\end{array}\right],
\end{aligned}
$$

with $N n$ and $N v$ are the number terms in the Fourier's series for the computation of no-load local quantities, the unit matrix $Q_{0 n n}$ has $N n \times N n$ coefficients, the diagonal matrices $Q_{1 n n} \sim Q_{4 n n}$ have $N n \times N n$ coefficients, the matrices $\quad Q_{5 n v i} \sim Q_{6 n v i}$ and $Q_{7 v n i} \sim Q_{10 v n i}$ have $N n \times N v$ and $N v \times N n$ coefficients respectively, the diagonal matrix $Q_{11 v v i}$ has $N v \times N v$ coefficients, and the matrices $K_{1 n} \sim K_{4 n}$ have $N n \times 1$ coefficients which depend on $\Theta_{r s}$. The corresponding elements in the matrices are derived in line with the work done by one of the authors [12].

It can be noted that (5) for each $\Theta_{r s}$ consists of $6 \cdot N n+Q_{p} \cdot N v$ equations and that many unknown variables. Based on this 2-D exact analytical model, the no load magnetic flux density of a slotted PMBLDC motor in all regions is done in MATHCAD environment.

\section{II.2. Analytical Results}

The closed form solution derived in the previous section is used for designing an experimental radial magnetized Slotted PMBLDC Motor within the dimensional requirements of $(104 \times 40) \mathrm{mm}$ for spacecraft applications. The basic design details obtained for the initially designed slotted PMBLDC motor developed with radial magnetized PMs is shown in Table I. 
TABLE I

DESIGN DETAILS OF THE EXPERIMENTAL SLOTTED PMBLDC MOTOR

\begin{tabular}{ll}
\hline Parameter & Value \\
\hline Dimension & $\Phi(104 \mathrm{x} 40) \mathrm{mm}$ \\
Supply voltage & $28 \mathrm{~V}$ \\
No. of phases $(m)$ & 3 \\
No. of poles $(2 p)$ & 12 \\
No. of slots $\left(Q_{s}\right)$ & 36 \\
Resistance/Phase & $3.37 \Omega$ \\
Air-gap thickness & $0.5 \mathrm{~mm}$ \\
Permanent magnet & $\mathrm{Sm}_{2} \mathrm{CO}{ }_{17}$ \\
Magnet thickness & $4 \mathrm{~mm}$ \\
Axial length of PMs & $30 \mathrm{~mm}$ \\
Radius of the stator yoke surface $\left(R_{s y}\right)$ & $50.5 \mathrm{~mm}$ \\
Radius of the stator surface $\left(R_{s}\right)$ & $44.5 \mathrm{~mm}$ \\
Radius of the PM's surface $\left(R_{m}\right)$ & $44 \mathrm{~mm}$ \\
Radius of the rotor yoke surface $\left(R_{r}\right)$ & $40 \mathrm{~mm}$ \\
\hline
\end{tabular}

The Fig. 2 shows the radial component for the no load magnetic flux density of the designed radial magnetized slotted PMBLDC motor under one pole pitch from the 2$\mathrm{D}$ exact analytical model. The designed slotted motor has 36 slot and teeth combination and the number of stator slots per pole is 3 as shown in Table I.

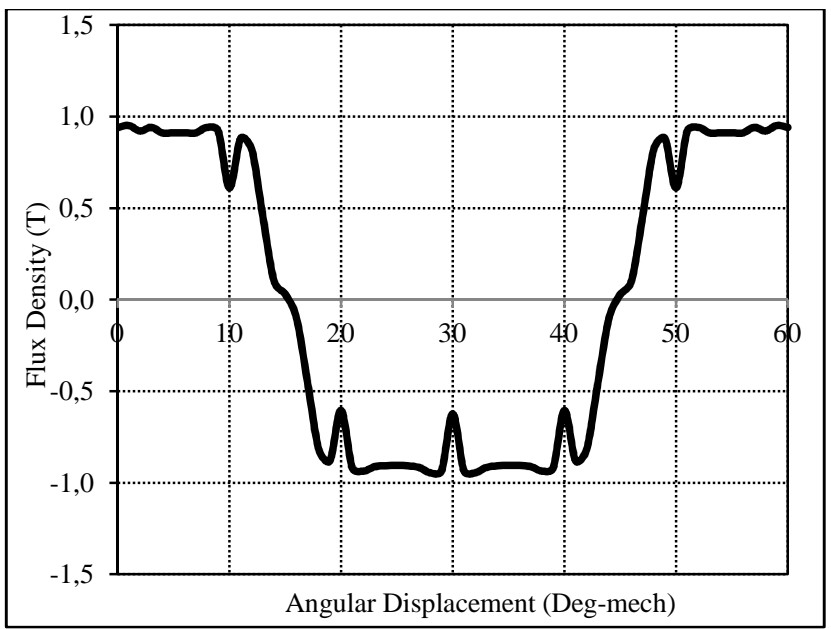

Fig. 2.Waveform of the radial component for the no load magnetic flux density in the air-gap under one pole pitch (Analytical Result)

From Fig.2, it is clear that significant amount of harmonics is present in the magnetic flux density waveform due to the effect of slotting. The basic design parameters obtained from the analytical model is used to model the machine in FE. The optimization of the machine has been carried out in FE so as to reduce the cogging component of torque to suit space applications and the results are explained in the following section.

\section{II.3. FE Optimization and Results}

The presence of cogging torque in slotted motor configurations is significant due to the interaction between the rotor magnetic flux and the variation of stator reluctance caused by slotting. There are different methods available in literature [15-16] for the reduction of cogging torque in these motors. The most significant methods among them are: i) skewing of the stator slots or PMs, ii) change in magnet pole-arc to pole-pitch ratio, iii) providing notches in stator teeth, iv) shifting of PM pole pairs and v) adopting fractional slot pitch combination. The previous research done by the authors [17], clearly reveal the advantages of adopting fractional slot pitch configuration for reducing cogging torque in slotted PMBLDC motors. The amplitude of the cogging torque comes down when the frequency of the cogging cycles increases. The number of cogging cycles in one complete mechanical rotation is calculated by taking the least common multiple of the number of stator slots (i.e., $Q_{s}$ ) and the number of poles (i.e., $2 p$ ). Based on this strategy, the 12 poles, 36 slot motor designed analytically, is analyzed using FE with stator of different slot numbers. From the FE analysis, it is found that the cogging torque reduces drastically, if 37 slot configuration is selected in the stator instead of 36 .

The flux distribution of the optimized 37 slot, 12 poles slotted PMBLDC Motor is shown in Fig. 3. Fig. 4 shows a comparison of the developed torque pattern under one pole pitch for a 36 slots and 37 slots radial magnetized PMBLDC motor. The torque pulsation in the developed torque is very high for a 36 slots combination which is detrimental for the positional stability for precise space applications.


Fig. 3.Flux Distribution of the optimized 37 slots, 12 poles PMBLDC motor (FE Results) 


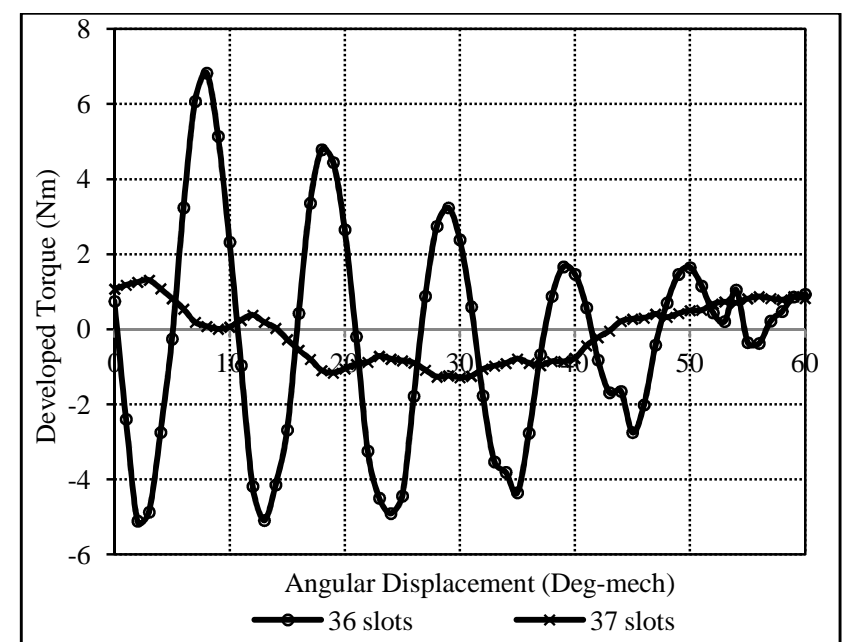

Fig. 4. Comparison of the developed torque patterns of a 12 poles, 36 slots and 37 slots PMBLDC motor (FE Results)



Fig. 5. Comparison of the cogging torque patterns of a 12 poles, 36 slots and 37 slots PMBLDC motor (FE Results)

But the developed torque pattern has the least torque pulsations when a 37 slots combination is adopted. Fig. 5 shows the cogging torque pattern of 36 slot and 37 slot combinations. The magnitude of the cogging torque is very much reduced in a 37 slot combination when compared to a 36 slot PMBLDC motor as is evident from Fig.5. The machine is found to develop a peak developed torque of $1.3 \mathrm{Nm}$ and an average torque of $0.723 \mathrm{Nm}$. But the magnitude of cogging torque even in the optimized model ( 37 slots, 12 poles), is found to be $20 \%$ of the developed torque which is higher than that of a hybrid stepper motor of compatible size.

Hence another class of PMBLDC motors, i.e., a Slotless PMBLDC configuration is investigated to satisfy the least cogging torque requirements of the spacecraft application. The use of ferromagnetic material on the rotor can be avoided in halbach magnetization [18], thus reducing the core losses and permitting high torque to inertia ratio as required for space applications. This is not the case with radial and parallel magnetization. Hence a Slotless halbach air core PMBLDC machine is considered for further analysis.

\section{Analysis of a Slotless PMBLDC Motor}

\section{III.1. Analytical Modeling}

For deriving the analytical model of a slotless Halbach magnetized PMBLDC motor, scalar magnetic potentials derived from the solutions of Laplace's and Poisson's equations is used. In order to obtain analytical solution for the field distribution produced in a multi-pole Halbach machine, the following assumptions are made:

i) The PM is oriented according to Halbach magnetization and is fully magnetized in the direction of magnetization.

ii) The effect of finite axial length is neglected.

iii) The back iron is infinitely permeable.

Fig. 6 shows a zero cogging PMBLDC motor with Halbach array. Unlike that of conventional slotted type PMBLDC motor, the zero cogging PMBLDC motor

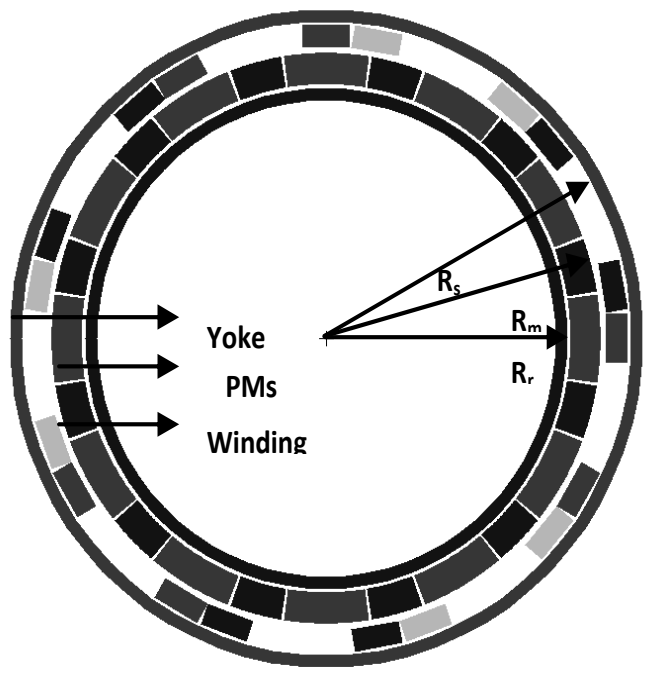

Fig. 6. Zero Cogging PMBLDC Motor with Halbach Array

employs slotless stator winding. Concentrated type of winding is employed in the design, as it gives less end winding and avoids overlapping of phase windings when compared to distributed windings. The inherent self shielding property of Halbach machines over radial and parallel magnetized machines makes it an ideal choice for employing coreless configuration. From the schematic diagram of the machine shown in Fig.6, the region inside the Halbach array is considered as air due to coreless configuration. Hence the complete solution for the internal rotor Halbach array zero cogging motor under study is obtained by the solution of Laplace's and quasi-Poisson's equation in the air-gap and in the PMs respectively and by the application of boundary conditions.

The final mathematical model for calculating the open air- 
gap flux density in a internal rotor zero cogging Halbach array motor has been developed in [19-20]. They are formulated in polar coordinates and account for relative recoil permeability of the PMs. The radial component of the magnetic flux density in the air-gap is defined by,

$$
\begin{aligned}
& B_{r 1}=-\frac{4 p \cdot B_{r m}}{M_{0} \cdot\left(1+\mu_{r m}\right)} \cdot \frac{1}{(1+p)} \cdot\left[1-\left(\frac{R_{r}}{R_{m}}\right)^{p+1}\right] \\
& {\left[\left(\frac{r}{R_{s}}\right)^{p-1} \cdot\left(\frac{R_{m}}{R_{s}}\right)^{p+1}+\left(\frac{R_{m}}{r}\right)^{p+1}\right] \cdot \cos \left(p \cdot \Theta_{s}\right) } \\
& M_{0}=2 \cdot\left\{\begin{array}{l}
\left(\frac{1-\mu_{r m}}{1+\mu_{r m}}\right)^{2} \cdot\left(\frac{R_{r}}{R_{m}}\right)^{2 p}-1 \\
-\left[1-\left(\frac{R_{r}}{R_{m}}\right)^{2 p}\right] \cdot \frac{\left(1-\mu_{r m}\right)}{\left(1+\mu_{r m}\right)} \cdot\left(\frac{R_{m}}{R_{s}}\right)^{2 p}
\end{array}\right\}
\end{aligned}
$$

where $\mu_{r m}$ is the relative recoil permeability of the PMs, $R_{r}$ is the internal radius of the magnet, $R_{m}$ is the magnet outer radius, $R_{s}$ is the stator outer bore radius. The analytical model developed for Halbach array slotless PMBLDC motor was utilized for further analysis in MATLAB environment.

\section{III.2. Analytical Results and Discussion}

The analytical expressions given in (7) is used for computing the radial component of the mean magnetic flux density in the air-gap for a Halbach slotless internal rotor PMBLDC motor with the required specifications of $(104 \times 40)$ mm. Fig. 7 gives the variation of peak air gap flux density at mean air gap radius with pole pair number of the Halbach slotless air core PMBLDC machine to be designed. The length of the magnetic flux path in a Halbach magnetized rotor is dependent on the pole pair number and hence there exist an optimum number of poles at which the flux density is maximum. The same is not applicable for radial and parallel magnetized machines since the length of the magnetic flux is constant (equal to the magnetic thickness) [21]. It is seen from Fig. 7, that the optimum flux density is obtained when the total number of rotor pole pairs is selected as 6.With the increase in length of the PM, even though the mean air gap flux density increases, the space available for accommodating the stator windings decreases. Hence based on the tradeoff between electrical and magnetic loading optimized values of length of PM and total number of poles pole are chosen as $6 \mathrm{~mm}$ and 12 respectively. The Fig. 8 shows variation of the mean air gap flux density under one pole pitch of the Halbach slotless air core PMBLDC designed. Unlike that of a slotted PMBLDC motor configuration, the flux density waveform at the mean air gap of a Halbach array slotless

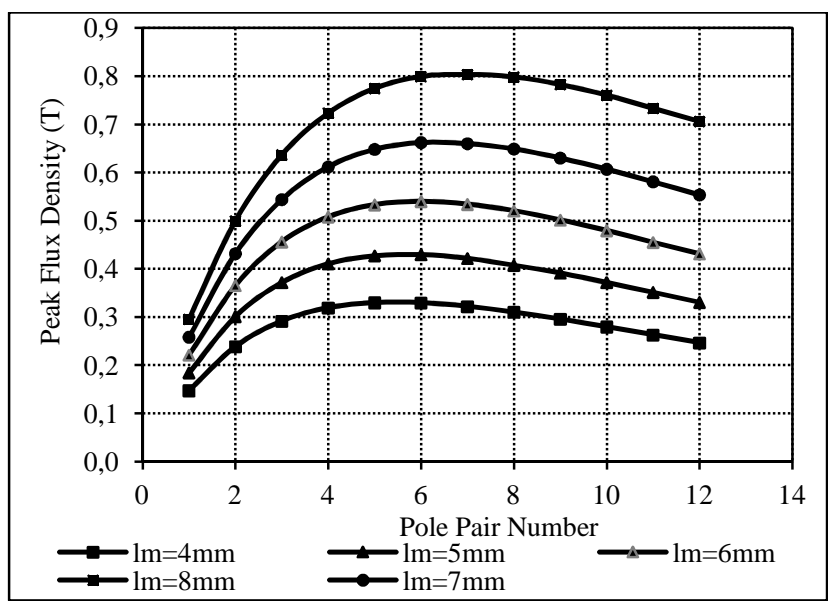

Fig. 7. Variation of peak $B_{r 1}$ with change in length of PM and pole pairs (Analytical Results)

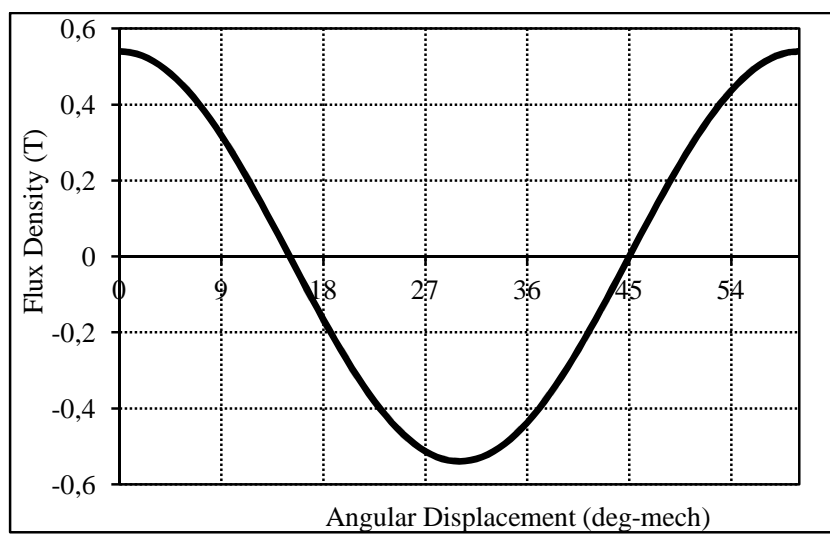

Fig. 8. Variation of mean air gap flux density under one pole pitch (Analytical Results)

motor is free of any harmonic content .This is due to the adoption of slotless topology. Also this design is free of the cogging torque component as stator is having no teeth. Hence a zero cogging Halbach array PMBLDC motor confirming to the ideal torque requirements of the spacecraft application is designed. A brief design data of the developed zero cogging Halbach array PMBLDC motor is given in Table II.

TABLE II

DESIGN DETAILS OF THE HALBACH ARRAy SLOTLESS PMBLDC Motor

\begin{tabular}{ll} 
Parameter & Value \\
\hline Dimension & $\Phi(104 \times 40) \mathrm{mm}$ \\
Supply voltage & $28 \mathrm{~V}$ \\
No. of phases $(m)$ & 3 \\
No. of poles $(2 p)$ & 12 \\
No. of stator coils & 9 \\
Resistance/Phase & $3.37 \Omega$ \\
Air-gap thickness & $0.5 \mathrm{~mm}$ \\
Permanent magnet & $\mathrm{Sm}_{2} \mathrm{CO}_{17}$ \\
No. of PMs & $12+12$ \\
Axial length of PMs & $30 \mathrm{~mm}$ \\
Position sensor & Hall element \\
Magnet thickness & $6 \mathrm{~mm}$ \\
Radius of the stator surface $\left(R_{s}\right)$ & $50 \mathrm{~mm}$ \\
Radius of the PM's surface $\left(R_{m}\right)$ & $44 \mathrm{~mm}$ \\
Radius of the rotor yoke surface $\left(R_{r}\right)$ & $38 \mathrm{~mm}$ \\
\hline
\end{tabular}




\section{III.3. FE Results and Discussion}

The basic design parameters obtained from the analytical results of a slotless PMBLDC motor with Halbach array, such as the length of the PM and the number of pole pairs is used to model the machine in FE for further optimization. Equal proportion of the main and flux focusing magnet $(50+50)$ is used for modeling the Halbach array in FE.

The 2-D FE analysis is carried out as the machine is axisymmetric. The commercial FE Software package, i.e., Maxwell 2-D, is used for the analysis. Fig. 9 shows the flux density plot and the magnetic vector plot of the designed zero cogging Halbach motor. From the flux pattern, it is clear that flux focusing PM acts as a path for flux between adjacent poles and hence reduces the flux in the back iron. Fig. 10 gives a comparison of the torque developed by the machine at $1 \mathrm{~A}$ excitation obtained from analytical and FE results. FE results are found in close agreement to that of obtained from the analytical results. Therefore, the slight discrepancy between the analytical and FE results can be attributed to the realization of the Halbach array using discrete magnet segments which has no significant effect on practical applications. The magnets are assumed to be ideally Halbach magnetized for the analytical modeling whereas in the FE modeling Halbach array is realized using discrete magnet segments.



Fig. 9. Flux Distribution of the machine (FE Results)



Fig. 10. Comparison of the developed torque patterns obtained from analytical and FE Results

The developed torque pattern becomes more sinusoidal and suits only sine-cosine drives when higher number of segments per pole is used for the formation of Halbach array [19], [22], [23]. Hence, considering the fabrication feasibility and the requirement of a PMBLDC Motor drive, a two segment/pole configuration is used for realizing the Halbach array.

From the FE results shown in Fig.10, the zero cogging Halbach array PMBLDC motor designed is found to develop a peak torque of $0.84 \mathrm{Nm}$ at $1 \mathrm{~A}$ excitation and an average torque of $0.55 \mathrm{Nm}$ under one pole pitch.

\section{FE Optimization of Slotless PMBLDC Motor}

\section{IV.1. Comparison of radial and halbach array configurations}

In order to highlight the advantages of halbach magnetization over conventional radial magnetization, the performance of the zero cogging Halbach array PMBLDC motor designed in the previous section is compared with that of a conventional slotless PMBLDC motor employing radial magnetization. The motor design envelopes are taken same for both the cases. Fig. 11 shows the comparison of flux density pattern of radial and Halbach magnetized slotless PMBLDC motors obtained from FE results. The inherent self shielding capacity of Halbach array permits the use of coreless configuration unlike that of radial magnetization as is evident from Fig. 11. The Halbach array concentrates the magnetic flux more on one side of magnets, (i.e. in the air-gap region) whereas there has to be a return path for flux in radial magnetization. This property of the slotless Halbach array motor makes it superior over its radial counterpart in terms of reduced core losses, high torque density, high torque to inertia ratio and zero magnetic stiction required for spacecraft application requirements. 

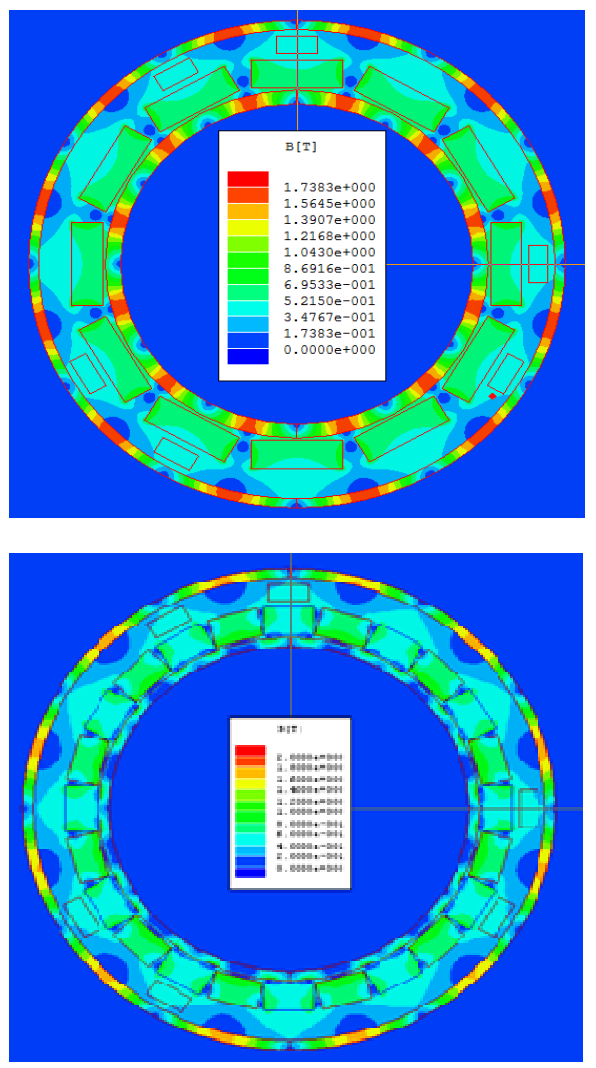

Fig. 11. Comparison of the flux density pattern of radial and halbach magnetized slotless PMBLDC Motors

Fig. 12 shows a comparison of the developed torque patterns of radial and Halbach magnetized slotless PMBLDC motors obtained from FE Results. From Fig. 12 it is seen that the developed torque pattern is more sinusoidal (i.e. more torque ripple) with Halbach motors suiting sine-cosine drives whereas in the radial motor it is more trapezoidal, ideally suited for PMBLDC motors, thereby reducing torque ripple.

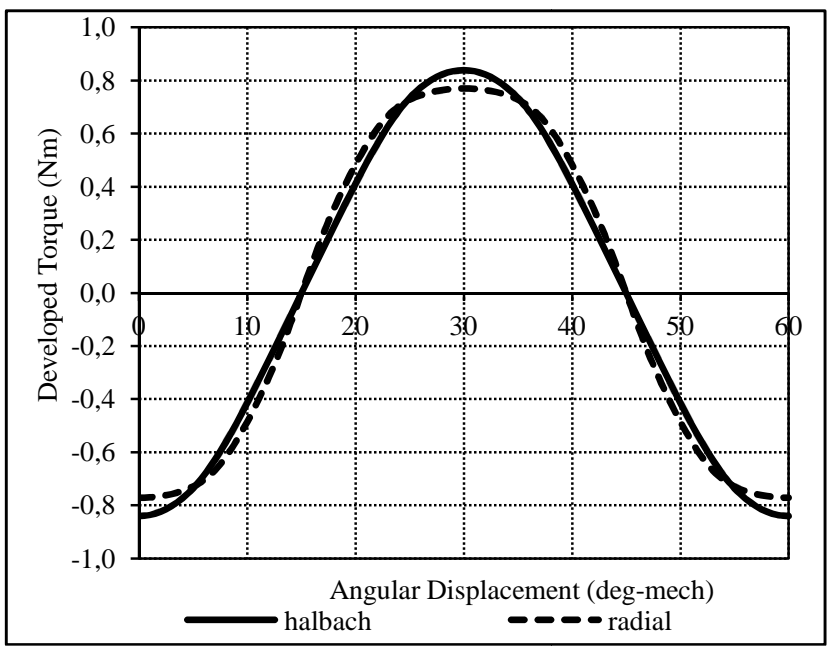

Fig. 12. Comparison of the flux density pattern of radial and halbach magnetized slotless PMBLDC Motors
TABLE III

COMPARISON BETWEEN RADIAL AND HALBACH SLOTLESS PMBLDC MOTOR CONFIGURATIONS

\begin{tabular}{cccc}
\hline Configuration & $\begin{array}{c}\text { Average } \\
\text { Torque }(\mathrm{Nm})\end{array}$ & $\begin{array}{c}\text { Peak Torque } \\
(\mathrm{Nm})\end{array}$ & $\begin{array}{c}\text { Torque } \\
\text { Ripple }(\%)\end{array}$ \\
\hline $\begin{array}{c}\text { Slotless Radial } \\
\text { magnetized PMBLDC } \\
\text { Motor }\end{array}$ & 0.55 & 0.77 & 12.44 \\
$\begin{array}{c}\text { Slotless Halbach array } \\
\text { PMBLDC Motor }\end{array}$ & 0.54 & 0.84 & 23.19 \\
\hline
\end{tabular}

Table III shows a comparison of performance indices of the two configurations of slotless PMBLDC motors. It is evident that even though the peak torque developed in the Halbach motor designed with equal proportion between flux focusing and main magnet $(50+50)$ is superior than the radial one, the amount of torque ripple present should be reduced further for ideal torque requirements of the space application. The next section deals with the optimization of the slotless Halbach array PMBLDC motor designed.

\section{IV.2. Optimization of Slotless Halbach Array PMBLDC Motor}

Equal proportion between the flux focusing and main magnet is adopted $(50+50)$ is adopted for the basic design of the halbach array of slotless PMBLDC motor. The presence of high torque ripple persists with this basic design, in spite of its high torque density and zero cogging torque. Hence, for the ideal torque requirements of the spacecraft applications, this basic design is further optimized in FE by varying the proportion between main and flux focusing magnets. The variation of the developed torque pattern with the change in proportion of main and flux focusing magnet is shown in Fig. 13. Here, it is observed that with the increase in proportion of flux focusing magnet to the main magnet, the pattern becomes more sinusoidal with increase in peak torque.

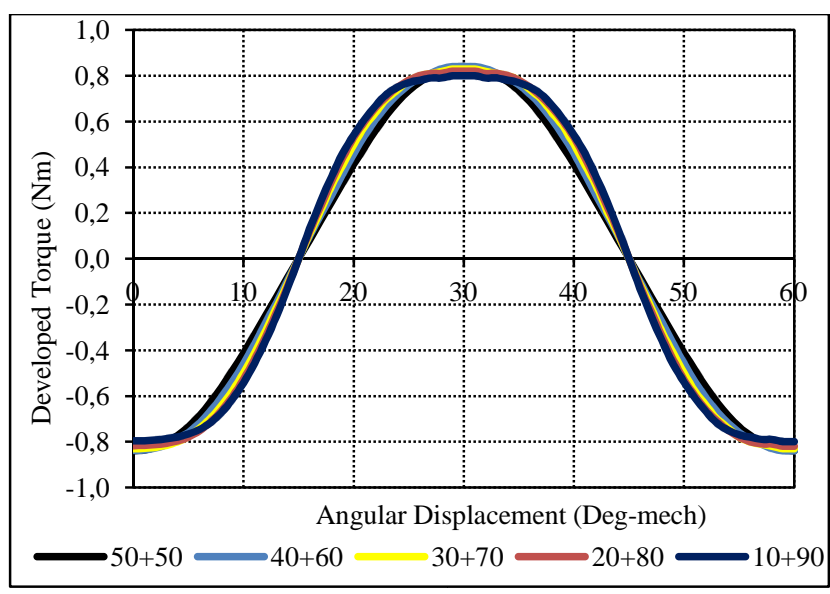

Fig. 13. Developed torque pattern with change in proportion of flux focusing and main magnet (FE Results) 
TABLE IV

VARIATION OF PERFORMANCE PARAMETERS WITH THE CHANGE IN MAGNET PROPORTIONS

\begin{tabular}{ccccc}
\hline $\begin{array}{c}\text { Main } \\
\text { magnet }(\%)\end{array}$ & $\begin{array}{c}\text { Flux focusing } \\
\text { magnet }(\%)\end{array}$ & $\begin{array}{c}\text { Average } \\
\text { Torque } \\
(\mathrm{Nm})\end{array}$ & $\begin{array}{c}\text { Peak } \\
\text { Torque } \\
(\mathrm{Nm})\end{array}$ & $\begin{array}{c}\text { Torque } \\
\text { Ripple } \\
(\%)\end{array}$ \\
\hline 50 & 50 & 0.54 & 0.84 & 23.19 \\
60 & 40 & 0.56 & 0.84 & 18.39 \\
70 & 30 & 0.58 & 0.83 & 14.45 \\
$\mathbf{8 0}$ & $\mathbf{2 0}$ & $\mathbf{0 . 5 9}$ & $\mathbf{0 . 8 2}$ & $\mathbf{1 2 . 1 1}$ \\
90 & 10 & 0.58 & 0.80 & 10.24 \\
\hline
\end{tabular}

The ripple increases (i.e. more sinusoidal) with the increase in proportion of flux focusing magnet to the main magnet, which will be more suitable for sine-cosine drives. The variation of peak torque, average torque and ripple with this change is tabulated in Table IV. As per Table IV, 10+90 configuration develops the least torque ripple of $10.24 \%$. However for the spacecraft application requirements of a torquer motor, $20+80$ configuration of the magnets which provides higher values of peak torque and average torque were chosen without compromising much on the torque ripple. Based on these results, the proportion between the flux focusing and main magnet is chosen as $20+80$ for the optimum design of the Halbach array of Slotless PMBLDC motor. Table $\mathrm{V}$ gives a comparison of the performance parameters of the Surface Mounted PMBLDC motors analysed and it is seen from the table that optimized Slotless Halbach Array PMBLDC motor topology eliminates the cogging component of the torque completely without much reduction in the developed torque component. Moreover, it yields ideal trapezoidal torque characteristics similar to radial magnetization with significant increase in peak as well as average torque.

TABLE V

COMPARISON OF SURFACE MOUNTED PMBLDC MOTOR CONFIGURATIONS

\begin{tabular}{ccccc}
\hline Configuration & $\begin{array}{c}\text { Average } \\
\text { Torque } \\
(\mathrm{Nm})\end{array}$ & $\begin{array}{c}\text { Peak } \\
\text { Torque } \\
(\mathrm{Nm})\end{array}$ & $\begin{array}{c}\text { Torque } \\
\text { Ripple } \\
(\%)\end{array}$ & $\begin{array}{c}\text { Cogging } \\
\text { Toque } \\
(\%)\end{array}$ \\
\hline $\begin{array}{c}\text { Slotless Halbach Array } \\
\text { PMBLDC Motor }\end{array}$ & $\mathbf{0 . 5 9}$ & $\mathbf{0 . 8 2}$ & $\mathbf{1 2 . 1 1}$ & $\mathbf{0}$ \\
$\begin{array}{c}\text { (Optimized design, } \\
\text { 20+80) }\end{array}$ & & & & \\
$\begin{array}{c}\text { Slotless Halbach array } \\
\text { PMBLDC Motor } \\
\text { (Basic Design, 50+50) }\end{array}$ & 0.54 & 0.84 & 23.19 & 0 \\
$\begin{array}{c}\text { Slotless Radial magnetized } \\
\text { PMBLDC Motor }\end{array}$ & 0.55 & 0.77 & 12.44 & 0 \\
$\quad$ & & & & \\
$\begin{array}{c}\text { Slotted PMBLDC Motor } \\
\text { (Optimized design) }\end{array}$ & 0.72 & 1.3 & 33.26 & 20 \\
\hline
\end{tabular}



Fig. 14. Comparison of the developed torque pattern of radial and optimized Halbach array slotless PMBLDC Motors (FE Results)

Hence, a slotless Halbach array PMBLDC motor topology with $20+80$ proportion between flux focusing and main magnet is found to be the best topology among the surface mounted PMBLDC motor configurations to cater the needs for precise spacecraft applications [Fig. 14].

\section{Conclusion}

The optimal design of a surface mounted PMBLDC meant for spacecraft applications is carried out. Two types of machine configurations such as slotted PMBLDC and slotless PMBLDC with and without Halbach array are compared with the help of analytical and FE methods. It is found that unlike that of slotted PMBLDC motor, a slotless PMBLDC motor with Halbach array develops zero cogging torque. The designed Halbach array motor is further optimized in FE to get ideal trapezoidal torque characteristics similar to radial motors with increase in both average and peak torque. The machine being coreless has zero magnetic stiction. The optimal design of slotless Halbach Array PMBLDC machine is found to develop a peak torque of $0.82 \mathrm{Nm}$ at $1 \mathrm{~A}$ excitation and is found to meet the required design requirements for spacecraft applications.

\section{Acknowledgements}

The authors would like to thank Indian Space Research Organisation Inertial Systems Unit, Department of Space, Government of India, Cochin University of Science \& Technology, Kerala, India and College of Engineering, Trivandrum, Kerala, India and University of Franche-Comte (UFC), Belfort, France for their help with this project. 


\section{References}

[1] Selection of Electric Motors for Aerospace Applications, NASA Document on Preferred Reliability Practices, Practice No. PD-ED1229, pp. 1-6.

[2] B. Ackermann, and R. Sottek, Analytical Modeling of the Cogging Torque in Permanent Magnet Motors, Electrical Engineering, vol. 78, no.2, pp. 117-125, 1994 .

[3] T. Sebastian and V. Gangla, Analysis of Induced EMF Waveforms and Torque Ripple in a Brushless Permanent Magnet Machine, IEEE Trans. on Ind. Appl., vol.32, no. 5, pp. 195-200, Jan./Feb. 1996.

[4] F. Dubas and C. Espanet, Semi-Analytical Solution of Cogging Torque in SMPMM, IEEE COMPUMAG'09 Conference, Florianopolis, Brazil, November 2009.

[5] F. Dubas, and C. Espanet, "Slotting Effect in Permanent-Magnet Motors via 2-D Exact Sub-Domain Model", ELECTRIMACS Conference, Cergy-Pontoise, France, June 2011.

[6] Seyed Amin Saied, Karim Abbaszadeh, Cogging Torque Reduction in BLDC Motors \& PMSM Using Dual Structures, International Review on Modelling and Simulations, vol. 2, n. 1, pp. 35-41, February 2009.

[7] S. Sadoghi and L. Parsa, Multiobjective Design optimization of Five-Phase Halabach Array Permanent-Magnet Machines, IEEE Trans. on Magn., vol. 47, no. 6, pp. 1658-1666, June 2011.

[8] R.P. Praveen, M.H. Ravichandran et.al., Design and Analysis of a Hybrid Stepper motor for Actuating the Gimbal of Control Moment Gyroscope, International Review of Electrical Engineering, vol.5, no. 4, Part-A, pp. 1488-1495, August 2010.

[9] R.P. Praveen, M.H. Ravichandran et.al., Design and Finite Element Analysis of Hybrid Stepper motor for Spacecraft Applications, IEEE IEMDC, pp. 1051-1057, May 2009.

[10] T. Kenjo and S. Nagamori, Permanent Magnet and Brushless DC Motors (Clarendon Press, Oxford, 1985).

[11] T.J.E. Miller, Brushless Permanent Magnet and Reluctance Motor Drives (Clarendon Press, Oxford, 1989).

[12] F. Dubas and C. Espanet, Analytical Solution of the magnetic field in permanent magnet motors taking in to account slotting effect: No-load vector potential and flux density calculation, IEEE Trans. on Magn., vol. 45, no. 5, pp. 2097-2109, May 2009.

[13] F. Dubas and C. Espanet, Exact analytical model of the no-load flux density in the air-gap, the permanent-magnets and the rotor yoke for the surface mounted permanent-magnet motors, International Review of Electrical Engineering, vol. 2, no. 3, pp. 425-437, May 2007.

[14] Z.Q.Zhu, L.J.Wu et.al., "An accurate sub-domain model for Magnetic field computation in Slotted Surface-Mounted Permanent Magnet Machines", IEEE Trans. on Magn., vol. 46, no. 4, pp. 1100-1115, April 2010

[15] T. Li, G. Slemon, Reduction of Cogging torque in permanent magnet motors, IEEE Trans. on Magn., vol. 24, no 6, pp. 29012903, November 1988.

[16] S.Z.Li Zhu Jiang, Z.Q.Zhu et.al., Analytical methods for minimizing cogging torque in Permanent-Magnet Machines, IEEE Trans. on Magn., vol. 45, no. 4, pp. 2023-2031, March 2009.

[17] M.H. Ravichandran, V.T. Sadasivan Achari et.al., Remedial strategies for the minimization of cogging Torque in PMBDC motor possessing material saturation, IEEE PEDES, pp. 1-4, December 2006

[18] R.P. Praveen, M.H. Ravichandran et.al., Design and Analysis of Zero Cogging Brushless DC motor for Spacecraft Applications, IEEE ECTI-CON, pp. 254 -258, May 2010.

[19] R.P. Praveen, M.H. Ravichandran et.al., Design and Analysis of Enclosed Rotor Halbach Array Brushless DC motor for Spacecraft Applications, IEEE ICEM'10 Conference, Rome, Italy, pp. 1 -6, September 2010.

[20] Z.P. Zia and Z.Q. Zhu, Analytical Magnetic Field Analysis of Halbach Permanent magnet machines, IEEE Trans. on Magn., vol. 40, no. 4, pp. 1864-1872, June 2004.

[21] S.M. Jang, S.S. Jeong, Comparison of three types of PM Brushless machines for an electro-mechanical battery, IEEE Trans. on Magn., vol. 36, no. 5, pp. 3540-3543, Sept. 2001.
[22] Farshad Montazeri and Davood Arab Khaburi, A Modified Direct Torque Control for BLDC Motor Drives, International Review on Modelling and Simulations, vol. 3, n. 4, pp. 546-552, August 2010.

[23] M. Shafiei, M. Bahrami Kouhshahi, M. B. B. Sharifian, M. R. Feyzi, Position Sensorless for Controlling Brushless DC Motor Drives Based on Sliding Mode and RLS Estimators Using NSGAII Algorithm Optimization, International Review on Modelling and Simulations, vol. 4, n. 3, Part-A, pp. 1121-1130, June 2011.

\section{Authors' information}

${ }^{1} \mathrm{Ph} . \mathrm{D}$ Research Scholar, Cochin University of Science and Technology, Cochin, Kerala, India (Corresponding Author).

${ }^{2,3}$ Scientist Engineer, ISRO Inertial Systems Unit, Indian Space Research Organisation, Kerala, India.

${ }^{4,5}$ Professor, Cochin University of Science and Technology, Kerala, India.

${ }^{6}$ Associate Professor, University of Kerala, College of Engineering Trivandrum, Kerala, India.

${ }^{7}$ Assistant Professor, University of Franche-Comte (UFC), FEMTO-ST Institute, ENISYS Department, Belfort, France.

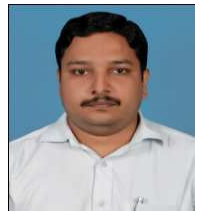

Praveen R.P. received the B.E.degree in Electrical and Electronics Engineering from M.S.University, Tirunelveli, India, in 2004, and the M.Tech degree in Electrical Machines from Kerala University, Kerala, India, in 2007. He is currently doing his research work at Cochin University of Science and Technology, India in association with Indian Space Research Organisation Inertial Systems Unit, India. He is also an Assistant Professor with the Electrical Department of Jyothi Engineering College, University of Calicut, India. His research interests include the design, analytical modeling, and optimization of permanent-magnet machines and drives. (e-mail : pravi_8200@yahoo.co.in)

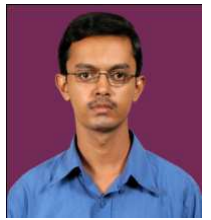

Ravichandran M.H received the B.E. in Electrical and Electronics Engineering from Bharathidasan University, Trichy, India, in 2000, and the M.E in Controls and Instrumentation Engg from CEG, Anna University, Chennai, India, in 2002. He is working as Engineer at ISRO Inertial Systems Unit, Trivandrum, India for last 7 years in the design, analysis and development of special electrical machines. His research interests include design, development and analytical modeling of special electrical machine like PMBDC, SRM and Hybrid Stepper Motor. (email: mh_ravichandran@vssc.gov.in)



V.T.Sadasivan Achari received the B.Tech degree in Electrical Engineering from the University of Kerala in 1982. He joined VSSSC/ISRO in 1983 in the Inertial Systems and instrumentation Division. He has worked extensively in the development of brushless DC motors for inertial actuators like reaction and momentum wheels. His field of interest is in the development of torque motors, design optimization for high torque production. (e-mail:vt_sadasivan@vssc.gov.in)

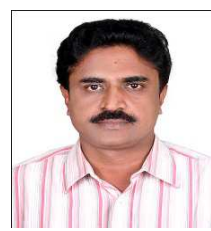

Dr. Jagathy Raj V.P. did his B.Tech in Electrical and Electronics Engineering from University of Kerala and M. Tech (Electronics with Communication as specialization) and MBA (Systems and Operations Management) from Cochin University of Science and Technology. He was awarded Ph.D in Industrial Engineering and Management from Indian Institute of Technology (IIT), Kharagpur He has more than 20 years of teaching experience in both Engineering and Management courses both at undergraduate and postgraduate levels. He is currently a Professor with School of Management Studies, Cochin University of Science and Technology, Kerala, India. His research interests include Computer Simulation and 
Modeling, Total Quality Management, Information Systems, Electrical and Electronics Engineering etc. (e-mail : jagathy@ cusat.ac.in)

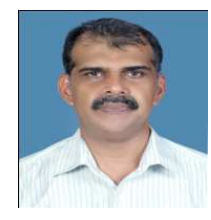

Dr. G. Madhu obtained B.Tech degree in engineering from the University of Calicut, India, in 1984 and Masters degree from Indian Institute of Technology Madras, India in 1986. He was awarded $\mathrm{Ph} . \mathrm{D}$ by the Cochin University of Science and Technology, Cochin, India in 1994. Dr. Madhu has more than 18 years of industrial experience. He has been with the School of Engineering of Cochin University of Science and Technology as Professor of Safety Engineering since 2004. His research interests include energy management, restoration of environmental quality and modeling of engineering systems. (e-mail: profmadhu@ rediffmail.com)

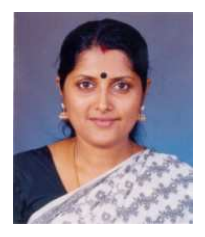

Dr G R Bindu was born in Kerala, India, on February 03, 1967.She took her M Tech Degree in 1992 and $\mathrm{PhD}$ in 2005 from University of Kerala.She worked as an Engineer in KERAFED and also as a Faculty in various Engineering Colleges in Kerala. She is currently an Associate Professor with the Department of Electrical Engineering, College of Engineering Trivandrum. Her areas of special interest are electromagnetic field theory, control and condition -monitoring of electric drives. (e-mail:bgr100@gmail.com)



Frédéric Dubas was born in Vesoul, France, on June 16, 1978. From 1997 to 2002, he studied at the University of Franche-Comté (UFC) in Vesoul and Belfort. He received his thesis in 2006 from the UFC, France, on the subject of the design and the optimization of high-speed surface mounted permanent magnet motor (SMPMM) for the drive of a Fuel Cell (FC) air-compressor. At the present time, he works with the Institute FEMTO-ST and ALSTOM Transports on the design and the optimization of induction machine as long as a research engineer. His special interest includes permanent magnet machines, high and low speed electrical motors, design and optimization of electrical machines, creative problem solving and electrical propulsion/traction. (email:fdubas@gmail.com) 